\title{
VIDEO-ASSISTED MINIMALLY INVASIVE MITRAL VALVE SURGERY
}

W. Randolph Chitwood, Jr., MD

Christopher L. Wixon, MD

Joseph R. Elbeery, MD

Jon F. Moran, MD

William H. H. Chapman, MD

Robert M. Lust, $\mathrm{PhD}$
Objective: This study was done to determine the potential benefits of minimally invasive mitral surgery performed with intraoperative video assistance. Methods: From May 1996 until March 1997, a minithoracotomy and video assistance were used in 31 consecutive patients undergoing mitral repair $(n=20)$ and replacement $(n=11)$. Their ages ranged from 18 to 77 years $(59 \pm 2.6$ years; mean \pm standard error of the mean). Ejection fractions were $35 \%$ to $62 \%(55 \% \pm 1.5 \%)$. Operations were done with either antegrade/retrograde $(n=10)$ or antegrade $(n=19)$ cold blood cardioplegia and a new transthoracic crossclamp or with ventricular fibrillation $(n=2)$. Peripheral arterial cannulation $(n=28)$ and pumpassisted right atrial drainage $(n=26)$ were used most often. Results: No hospital deaths occurred, but the 30 -day mortality was $3.2 \%$. Complications included deep venous thrombosis and a phrenic nerve palsy in one patient each. No patient had a stroke or required reoperation for bleeding. Postoperative echocardiography showed excellent valve function in all but one patient. Cardiopulmonary bypass and arrest times averaged $183 \pm 7.2$ and $136 \pm 5.5$ minutes, respectively. Compared with 100 patients having conventional mitral valve operations, these patients had significantly shorter hospitalization times $(8.6 \pm 0.5$ vs $5.1 \pm 0.9$ days, $p=0.05)$. Moreover, $81 \%$ of the later cohort were discharged between day 3 and 5 (3.6 \pm 0.2 days). Hospital charges $(\downarrow 27 \%, p=0.05)$ and costs $(\downarrow 34 \%, p<$ 0.05) were less than in conventional operations. Patient follow-up suggested minimal perioperative pain and rapid recovery. Conclusions: Early results suggest that video-assisted minimally invasive mitral operations can be done safely. These methods may benefit patients through less morbidity, earlier discharge, and lower cost. (J Thorac Cardiovasc Surg 1997;114:773-82)
$\mathrm{M}$ inimally invasive cardiac surgery may offer benefits over conventional sternotomy-based procedures. Recently, minimally invasive coronary bypass operations performed on the beating heart have been shown efficacious, especially in patients with left anterior descending coronary disease. ${ }^{1-3}$ Also, multivessel coronary operations, with intralu-

From the Division of Cardiothoracic Surgery, East Carolina University School of Medicine, Greenville, N.C.

Read at the Seventy-seventh Annual Meeting of The American Association for Thoracic Surgery, Washington, D.C., May 4-7, 1997.

Received for publication April 30, 1997; revisions requested May 21, 1997; revisions received June 16, 1997; accepted for publication June 18, 1997.

Address for reprints: W. Randolph Chitwood, Jr., MD, Department of Surgery, East Carolina University School of Medicine, Greenville, NC 27858.

Copyright (C) 1997 by Mosby-Year Book, Inc.

$0022-5223 / 97 \$ 5.00+0 \quad \mathbf{1 2 / 6 / 8 4 0 8 2}$ minal aortic balloon occlusion and cardioplegia, is being evaluated with great interest. ${ }^{4,5}$ Minimally invasive valve operations also have been performed through various incisions and may prove even more promising than coronary grafting, because detailed vascular anastomoses are not required. ${ }^{6-10}$ Despite widespread enthusiasm for these alternative operative approaches, caution has been emphasized, inasmuch as traditional coronary and valve operations have shown long-term success with ever-decreasing morbidity and mortality. ${ }^{11,12}$ Thus comparative operative safety, speed of recovery, discomfort, and cost, as well as long-term operative quality, remain important end points when these new procedures are evaluated.

\section{Methods}

In this study, 31 consecutive patients undergoing videoassisted minimally invasive mitral valve surgery (VMIMS) by one surgeon at East Carolina University, between May 


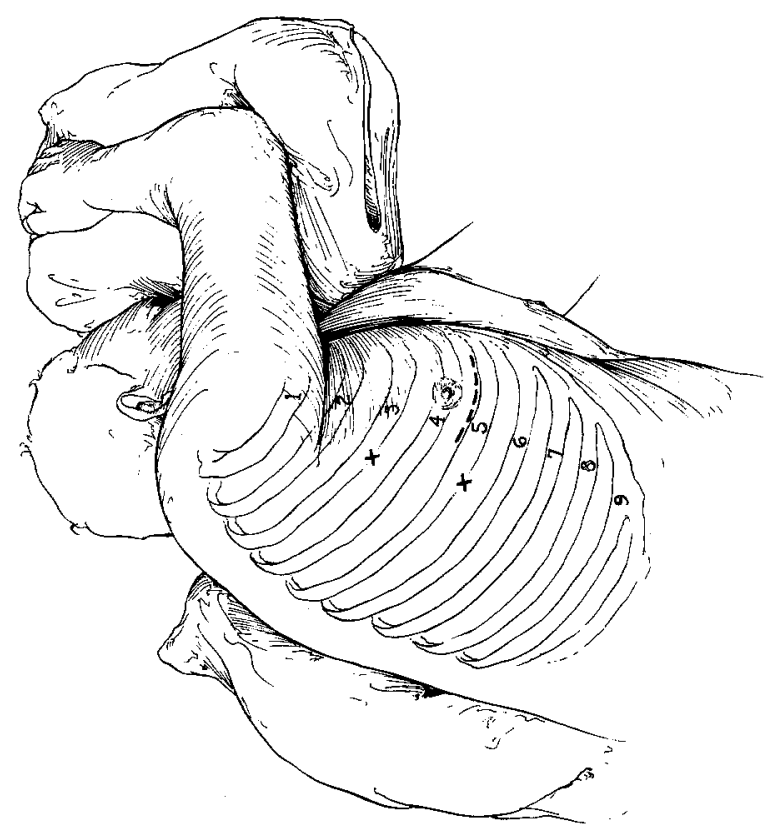

Fig. 1. The patient is positioned with the right side of the chest elevated 30 to 45 degrees. The incision is placed in the inframammary fold over the fifth rib. The cephalad $X$ mark indicates the insertion site for the transthoracic crossclamp and the caudal mark indicates the port-site for the thoracoscope. External defibrillator pads should be applied.

1996 and March 1997, were evaluated retrospectively. For comparison, the previous 100 standard mitral operations, done by the same surgeon between January of 1992 and 1997 , were analyzed retrospectively. The operating surgeon obtained informed consent after a detailed discussion of potential complications with the patient and family. All patients with isolated mitral disease, who were referred after May 1996, were offered a minimally invasive operation: however, two patients opted for a sternotomy and are included in the conventional group. Patients requiring concomitant coronary artery bypass grafting were excluded from both cohorts. Statistical comparisons for all data were made with the use of a $\chi^{2}$ analysis to calculate significance with respect to discrete variables. Operative and postoperative times were compared by means of a two-tailed $t$ test. Data are shown as \pm standard error of the mean.

Our operative approach for VMIMS has been described previously. ${ }^{13}, 14$ Patients were intubated for single left lung ventilation to facilitate atrial cannulation. For hemodynamic monitoring, a flow-directed pulmonary artery catheter was inserted through a right internal jugular vein introducer. External defibrillator pads were placed for postarrest cardioversion. An Omniplane transesophageal echocardiographic probe (Hewlett-Packard, Inc., Andover, Mass.) was positioned for preoperative, intraoperative, and postopera-

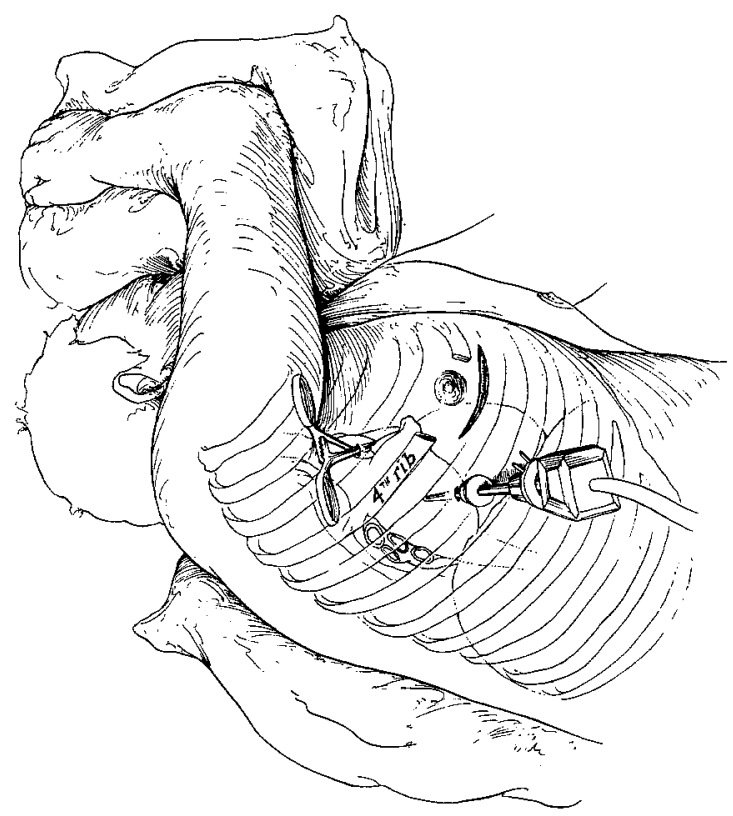

Fig. 2. A segment of the fourth rib anteriorly is removed. The transthoracic crossclamp is passed through the third intercostal space, in front of the superior vena cava, and through the transverse sinus to occlude the ascending aorta just caudal to the right pulmonary artery. Antegrade cardioplegia and aortic venting is provided by a videoscopically placed needle in the ascending aorta. The $5 \mathrm{~mm}$ telescope and thoracoscopic camera are shown inserted through a port in the fourth intercostal space. The camera port intercostal space is not selected until the superior pulmonary vein is identified.

tive studies that assessed ventricular function, intracardiac air removal, and procedural quality.

A measured $6 \mathrm{~cm}$ right anterolateral, inframammary incision was made and the thorax entered through the bed of a resected fourth rib segment, which obviated the need for rib spreading (Figs. 1 and 2). Modifications of standard perfusion and myocardial protection techniques were used throughout. In five early patients $(16 \%)$, both the femoral artery and vein were cannulated for arterial inflow and pump-assisted venous drainage. Direct atrial centrifugal pump-assisted drainage with a $23 \mathrm{~F}$ Bio-Medicus venous cannula (Medtronic Bio-Medicus, Eden Prairie, Minn.) was used in 26 patients (84\%). In 28 operations $(90 \%)$, femoral arterial inflow was established with the use of a flexible $17 \mathrm{~F}$ Bio-Medicus cannula inserted over a guide wire by the Seldinger technique. Either a diminutive femoral artery or aortoiliac occlusion necessitated transthoracic, direct aortic arch cannulation in three patients.

Cardiac arrest was induced by means of a newly designed transthoracic aortic crossclamp (Scanlan International, Inc., Minneapolis, Minn.) inserted through a $4 \mathrm{~mm}$ incision in the third intercostal space (Fig. 3). ${ }^{13,14}$ In 10 


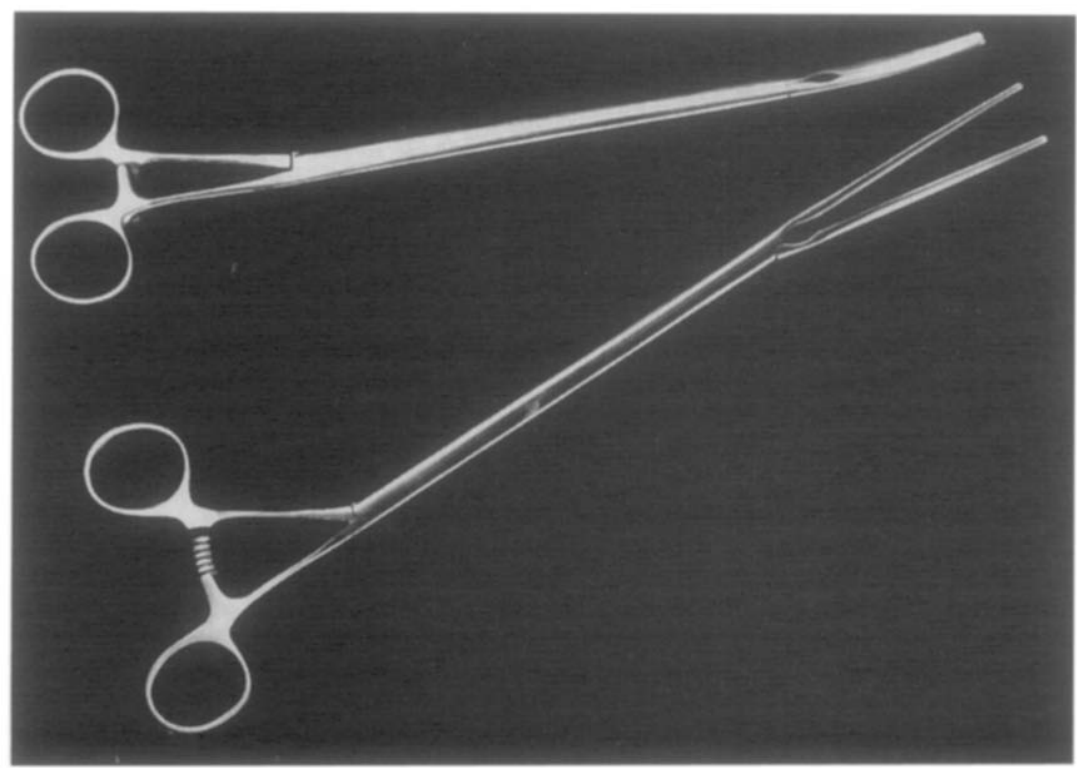

Fig. 3. The transthoracic crossclamp is shown in two pincer-tip lengths. The clamp mechanism works completely within the thorax (Scanlan International, Minneapolis, Minn.).

early patients (32\%), retrograde cold blood cardioplegia was used in combination with antegrade administration. However, in 19 patients (61\%), cold blood cardioplegic solution was given directly, and nearly continuously, through an aortic root catheter with potassium concentrations varied to maintain complete arrest. This catheter served as an aortic vent for air after crossclamp removal. Two operations (7\%) were done with the use of cold ventricular fibrillation. Systemic cardiopulmonary perfusion was maintained between $26^{\circ}$ and $28^{\circ} \mathrm{C}$ throughout both arrest and fibrillatory periods.

Either a 5 or $10 \mathrm{~mm}$ thoracoscope (0-degree or 30-degree view), connected to a three-chip Linvatec camera (Linvatec, Inc., Largo, Fla.), was inserted through a port placed through the fourth or fifth intercostal space (Figs. 1 and 2). Most frequently, a 5 $\mathrm{mm}$ telescope was passed into the heart through a 3 to $4 \mathrm{~cm}$ left atriotomy, made just anterior to the superior pulmonary vein. In many cases the 30 -degree view telescope overcame limitations inherent in two-dimensional visualization and facilitated intracardiac instrument manipulation. Most of each operation, including crossclamp placement, valve inspection, annular suture placement, chord replacement, and knot tying, was directed by thoracoscopic secondary vision. Posterior leaflet repairs and atriotomy closure often were done by direct vision, enhanced by long focal-distance loupes $(3.5 \times)$. Newly developed instruments (Scanlan International) provided retraction, valve tissue excision, knot tying, and suture cutting. For valve replacements, we used the St. Jude Medical mechanical prosthesis (St. Jude Medical, Inc., St. Paul, Minn.) with the posterior valvular-chordal apparatus always preserved. For valve replacements, 2-0 pledget-supported Ti-Cron sutures (Davis \& Geck, Inc., Danbury, Conn.) were used.

Annuloplasties were performed with the use of either a
Carpentier-Edwards Physio ring or the Cosgrove-Edwards band (Edwards CVS Division, Baxter Healthcare Corp., Irvine, Calif.) with 3-0 nonpledget-supported Ti-Cron annular sutures.

\section{Results}

Table I provides demographic data for patients in both the VMIMS and conventional sternotomy groups. Cohorts were similar for age, sex, and functional class. Despite a consecutive series, patients undergoing VMIMS had statistically better ventricular function. Eleven patients having minimally invasive procedures (35\%) underwent mitral valve replacement, and $20(65 \%)$ had a repair. Two patients undergoing valve replacement had degenerative disease and nine had rheumatic involvement. Valve diseases in patients having valve repair by VMIMS were similar to those in patients having sternotomy repairs and included degenerative disease $(n=12)$, annular dilatation $(n=4)$, rheumatic disease $(n=2)$, and healed endocarditis $(n=2)$. Operative techniques used for both groups are listed in Table II. No patients in the VMIMS group required a larger incision or a sternotomy, and no repairs resulted in a secondary replacement.

Table III relates perioperative clinical data for both groups. No hospital deaths occurred in the VMIMS group. However, one patient in New York Heart Association class I died suddenly 27 days after discharge of a presumed ventricular arrhythmia 
Table I. Demographic data

\begin{tabular}{lcc}
\hline & $\begin{array}{c}\text { VMIMS } \\
(n=31)\end{array}$ & $\begin{array}{c}\text { Conventional } \\
\text { stemotomy } \\
(n=100)\end{array}$ \\
\hline Age (yr) & $59 \pm 2.6$ & $59.3 \pm 1.4$ \\
Mean & $18-77$ & $29-78$ \\
Range & & \\
Sex & $12(39 \%)$ & $47(47 \%)$ \\
Men & $19(61 \%)$ & $53(53 \%)$ \\
$\quad$ Women & & \\
Preop. functional class & $13 \%)$ & $8(8 \%)$ \\
$\quad$ (NYHA) & $13(42 \%)$ & $42(42 \%)$ \\
Class I & $14(45 \%)$ & $40(40 \%)$ \\
Class II & $3(10 \%)$ & $10(10 \%)$ \\
Class III & & \\
Class IV & $29(93 \%)$ & $63(63 \%)^{*}$ \\
Ejection fraction (\%) & $2(6 \%)$ & $37(37 \%)^{*}$ \\
$>40 \%$ & & \\
$<40 \%$ & &
\end{tabular}

NYHA, New York Heart Association.

${ }^{*} p=0.001$.

(30-day mortality $=3.2 \%$ ). Autopsy revealed no demonstrable disease and normal prosthesis function. Comparatively, the 30-day mortality for patients having conventional sternotomy was $2.2 \%(p=$ not significant). One late death occurred at 3 months and was related to prosthetic valve endocarditis.

Cardiopulmonary perfusion and aortic crossclamp times averaged $183 \pm 7.2$ and $136 \pm 5.7$ minutes, respectively. No aortic clamp injuries occurred, and no difficulties were encountered in weaning patients from bypass. In several patients, the immediate postarrest electrocardiogram showed inferior lead changes, despite meticulous cardiac deairing. Others have noted similar alterations. ${ }^{15}$ However, the changes were transient and did not result in ventricular dysfunction, complex arrhythmias, or an infarction. By transesophageal echocardiography, postoperative ventricular function was qualitatively similar to each preoperative study. One patient who underwent VMIMS repair had a moderate residual leak but remains free of symptoms 10 months later.

As seen in Table III, both ventilatory and intensive care unit times tended to be lower than in conventional operations. Patients in the VMIMS group were extubated $12.1 \pm 1.6$ hours after the operation and were transferred from the intensive care unit $28.8 \pm 7.2$ hours after the operation. For the $97 \%$ of patients in the VMIMS group $(n=30)$ requiring 48 hours or less of ventilatory support, the overall stay in the intensive care unit was significantly less than for the sternotomy group $(p=0.05)$.
Table II. Operative techniques

\begin{tabular}{lcc}
\hline \multicolumn{1}{c}{ Operative technique } & $\begin{array}{c}\text { CMIMS } \\
(n=31)\end{array}$ & $\begin{array}{c}\text { Conventional } \\
\text { sternotomy } \\
(n=100)\end{array}$ \\
\hline Valve replacement & $11(35 \%)$ & $43(43 \%)$ \\
Valve repair & $20(65 \%)$ & $57(57 \%)$ \\
Annuloplasty alone & $8(40 \%)$ & $27(47 \%)$ \\
Annuloplasty-quad resection & $10(50 \%)$ & $17(30 \%)$ \\
Annuloplasty-chordal replacement & $2(10 \%)$ & $5(9 \%)$ \\
Annuloplasty-chordal transfer & $0(0 \%)$ & $8(14 \%)$
\end{tabular}

Overall, patients in the VMIMS group had a $5.1 \pm$ 0.9 day hospital stay, with $81 \%$ being discharged between the third and fifth postoperative days $(p=$ 0.001 ). In the last half of the series, the length of hospitalization fell to $3.6 \pm 0.3$ days. In both series a similar incidence $(20 \%)$ of new atrial fibrillation occurred in the postoperative period.

Operative complications for both groups are shown in Table IV. Major complications for the VMIMS group included deep venous thrombosis and a phrenic nerve palsy. The latter patient was supported with a ventilator for 17 days, representing the only individual requiring respiratory support for more than 48 hours. While in the intensive care unit, two patients required insertion of a bronchoscope to reexpand a right upper lobe that had collapsed as a result of endotracheal tube occlusion. In the VMIMS group there were no neurologic deficits or reexplorations for bleeding. By comparison, in the conventional sternotomy group $4 \%$ required reexplorations for bleeding and $3 \%$ had a transient stroke $(p=0.05)$. Transfusion volumes of packed red cells and frozen plasma were less than in the sternotomy group $(p=0.05)$. However, $38 \%$ of patients in the VMIMS group still received blood product transfusions.

Follow-up for patients undergoing VMIMS was $100 \%$ by visit and telephone call, averaging $23.6 \pm$ 2.5 weeks ( 5 to 47 weeks). Although no quantitative indices of discomfort or activity were measured, these patients reported little to no perioperative pain, with rapid return to normal activities. With the exception of the patients with deep venous thrombosis and phrenic nerve palsy, all patients who had had VMIMS were allowed to return to normal activities 2 weeks after discharge. Of the group, $48 \%$ improved by one functional class, $41 \%$ improved by two, and $7 \%$ improved by three functional classes after the operation. At follow-up $93 \%$ of patients in the VMIMS group were in functional class I or II.

To evaluate economic implications, we compared 
Table III. Perioperative data

\begin{tabular}{lcc}
\hline & VMIMS & $\begin{array}{c}\text { Conventional } \\
\text { sternotomy }\end{array}$ \\
\hline Crossclamp time (min) & $136 \pm 5.5$ & $92 \pm 3.6^{*}$ \\
Pump time (min) & $183 \pm 7.2$ & $116 \pm 4.4^{*}$ \\
PRBC infused (units) & $2.1 \pm 0.2$ & $3.6 \pm 0.4 \dagger$ \\
Hospital stay (days) & $5.1 \pm 0.9$ & $8.6 \pm 0.5^{*}$ \\
ICU stay: If ventilated <48 hr (hr) & $22.3 \pm 2.9$ & $48.7 \pm 8.2 \dagger$ \\
ICU stay: Total group (hr) & $28.8 \pm 7.2$ & $48.7 \pm 8.2$ \\
Ventilator period (hr) & $12.1 \pm 1.6$ & $22.7 \pm 5.2$ \\
Chest tube drainage (ml) & $623 \pm 99$ & $716 \pm 86$ \\
Patients transfused & 38 & 50 \\
Atrial fibrillation (\%) & & \\
$\quad$ Preoperative & 49 & 48 \\
Postoperative & 78 & 73 \\
New postoperative & 20 & 20
\end{tabular}

$P R B C$, Packed red blood cells; $I C U$, intensive care unit.

${ }^{*} p=0.001$

$\dagger p=0.05$.

hospital charge and cost data for the two groups (Table V). After cost adjustments for the valve or annuloplasty prosthesis, both charges and costs were found to be $27 \%$ and $34 \%$ less, respectively, for the VMIMS than for the conventional sternotomy group $(p=0.02)$. Charge and cost reductions resulted primarily from the reduced length of stay. Overall, time in the operating room for minimally invasive operations was approximately 1.6 hours longer than for conventional operations. At our hospital, operating room charges still remain procedure-based, masking potential time-dependent cost variances. Both operative groups were treated by the same critical care pathway; thus cost variations appeared unrelated to temporal changes in our protocol.

\section{Discussion}

Minimally invasive mitral valve surgery may offer advantages over operations done through conventional sternotomy incisions. Recent animal studies suggest that excellent myocardial preservation can be provided in near-closed chest models by means of intraaortic balloon occlusion and antegrade cardioplegia. ${ }^{15}$ In early 1996, using a similar technique (Heartport, Redwood City, Calif.) and a minithoracotomy, the Stanford group performed four minimally invasive mitral valve replacements in patients. ${ }^{10}$ Recently, the group from the University of Leipzig reported on 24 patients with mitral valve disease who were operated on successfully by means of the same technique. ${ }^{16}$ By May 1997, this balloon occlusive device had been used for mitral valve
Table IV. Operative complications

\begin{tabular}{llc}
\hline & VMIMS & $\begin{array}{c}\text { Conventional } \\
\text { sternotomy }\end{array}$ \\
\hline Transient neurologic (\%) & 0 & 3.0 \\
Delirium (\%) & 0 & 3.0 \\
Transient neuropathy (\%) & 3.2 & 0 \\
Bleeding: Reexploration (\%) & 0 & 4.0 \\
Heart block: Pacer (\%) & 0 & 2.0 \\
Gastrointestinal (\%) & 3.2 & 2.0 \\
Pneumonia (\%) & 0 & 3.0 \\
Renal insufficiency (\%) & 0 & 1.0 \\
Deep venous thrombosis (\%) & 3.2 & 0 \\
Phrenic nerve palsy (\%) & 3.2 & 0 \\
\hline
\end{tabular}

operations in 252 patients worldwide, with a $6.3 \%$ mortality. Others have shown that parasternal, transsternal, and hemisternotomy incisions may be used with direct aortic clamping. ${ }^{6-8}$ Recently, Cosgrove, Sabik, and Navia ${ }^{7}$ described 49 mitral operations performed through a small right parasternal incision with excellent results.

To achieve the potential benefits of VMIMS, we applied modifications of conventional operative technology, including (1) the minithoracotomy, (2) percutaneous transthoracic aortic occlusion, (3) video assistance, (4) centrifugal pump-assisted venous return, and (5) peripheral arterial perfusion. As noted by others, the parasternal and hemisternotomy approaches offer excellent intracardiac exposure; however, larger cardiac incisions are needed. Valve exposure may require division of the left atrial roof, interatrial septum, and sinoatrial nodal artery with possible early junctional arrhythmias. With the parasternal approach, an anterior chest wall defect results if costal cartilages are removed. The minithoracotomy is familiar, obviating these concerns, and offers excellent mitral exposure, especially when combined with video assistance. Recently, several authors have reiterated the merits of this surgical approach in congenital and valve surgery. ${ }^{18-22}$ Thus application to minimally invasive valve surgery seems ideal, because the anterolateral incision provides a direct, perpendicular view of the mitral orifice with minimal operative pain.

Transthoracic aortic clamp occlusion was not difficult and antegrade cardioplegia provided excellent cardiac protection. ${ }^{13,}{ }^{14}$ Video assistance was used to guide passage of the clamp through the transverse sinus and to occlude the aorta. No aortic clamp occlusion injuries resulted in these patients. To avoid injury to the right pulmonary artery and left 
Table V. Hospital charges versus cost

\begin{tabular}{lcc}
\hline & Hospital charges & $\begin{array}{c}\text { Hospital costs } \\
\text { per patient }\end{array}$ \\
\hline Conventional sternotomy $(n=100)$ & $\$ 42,413 \pm \$ 2,594$ & $\$ 27,049 \pm \$ 1,909$ \\
VMIMS $(n=31)$ & $\$ 30,985 \pm \$ 2,408$ & $\$ 17,884 \pm \$ 1,700$ \\
Mean difference in dollars & $\downarrow \$ 11,428^{*}$ & $\downarrow \$ 9,165^{*}$ \\
Difference in percent & $\downarrow 27 \%$ & $\downarrow 34 \%$ \\
\hline
\end{tabular}

$p<0.02$.

atrial appendage, we were careful along the posterior aorta. With VMIMS, ventral left atrial retraction displaces the aorta less than in sternotomy operations, usually maintaining aortic valve competence with an air-free aortic root. This made near continuous antegrade cardioplegia possible. The endovascular aortic clamp (Endoaortic Clamp, developed by Heartport, Inc., Redwood City, Calif.) provides intraluminal aortic occlusion and antegrade cardioplegia capabilities. However, balloon catheter insertion may have a higher potential for aortic dissection than direct occlusion. Moreover, in smaller patients and those with significant aortoiliac occlusive disease, passage of an intraaortic catheter may be impossible. In addition, proximal balloon migration could cause innominate artery occlusion, rendering untoward neurologic complications. At present, intraaortic occlusive balloons add significant supply costs $(\$ 5000)$ and precise positioning of the ascending aorta requires personnel support. For mitral valve operations, the percutaneous transthoracic clamp appears safe and requires no additional resources.

Cardiac surgery is the last specialty to use the benefits afforded by video assistance. To date, most port-access and sternal modification, or parasternal, valve operations have been done with the use of direct vision. The benefits of operative videoscopy are being recognized gradually by cardiac surgeons world-wide. Video assistance has been helpful for closed-chest internal thoracic artery harvests and closure of the ductus arteriosus. ${ }^{1-3,23}$ Recently, Kaneko and associates ${ }^{24}$ reported videoscopic assistance in mitral valve surgery done through an open sternotomy. In early 1996, Carpentier and cowork$\mathrm{ers}^{25}$ reported the first video-assisted mitral valve repair through a minithoracotomy using ventricular fibrillation. Three months later our group first performed a completely video-assisted mitral valve replacement through a minithoracotomy using the transthoracic aortic clamp and retrograde cardioplegia. ${ }^{13}$ Others have reported atrial septal defect closures and mitral reoperations facilitated by video assistance. ${ }^{17,26,27}$

In the 31 patients reported on in this study, video assistance was always helpful, and sometimes essential, for providing optimal instrument access to many intracardiac sites. Tissue excision, suture placement, prosthetic valve/ring positioning, and knot tying all were facilitated by thoracoscopic vision. In most instances, we used a 0-degree telescopic camera; however, the 30-degree telescope was helpful for viewing commissures and fibrous trigones, as well as for minimizing instrument conflicts. In some circumstances, had we not used video assistance, we would have had to enlarge the incision. Ventral left atrial retraction often was limited by the sternum, even when transthoracic retractors were used. In many circumstances, direct exposure of trigonal/commissural regions, the anterior anulus, and intracardiac papillary/chordal structures was difficult and visualization was enhanced through video assistance. Secondary vision was most beneficial in large or obese patients, in those with a deep thorax, and in individuals with large left atria. Operative video dexterity clearly improved with experience. However, as Lytle $^{11}$ has cautioned, the lack of three-dimensional perception still limits the full potential of this technique. Three-dimensional intracardiac cameras, now in development, may facilitate even less-invasive mitral operations.

Centrifugal pump-assisted, or suction, venous drainage worked well in this series. In nearly all VMIMS cases, arterial perfusion was established with a thin-walled femoral cannula inserted over a guide wire with the use of dilators. Although others have noted retrograde aortic dissections with minimally invasive coronary and mitral operations, no dissections occurred in this series. ${ }^{16}$ However, with femoral arterial cannulation, the hazard of dissection remains ever present, even with guide wire placement. Direct transthoracic aortic perfusion appears to be our next major challenge to obviate this concern. At present, our preferred method for per- 
forming minimally invasive mitral operations uses (1) a right minithoracotomy, (2) peripheral arterial perfusion, (3) central venous cannulation, (4) antegrade aortic root cold blood cardioplegia, (5) transthoracic clamp aortic occlusion, (6) video assistance with a $5 \mathrm{~mm}$ telescopic camera, and (7) the use of specialized instruments.

Despite the potential benefits of VMIMS, several concerns emanated from this early series and warrant discussion. As in any retrospective study, comparative shortcomings are inherent. However, if consecutive patient cohorts are compared, an overall notion of the benefits and disadvantages of VMIMS may be suggested. Although chest tube drainage in patients having minimally invasive procedures was similar to that of patients having conventional sternotomy, overall transfusion requirements and reexplorations for bleeding were less. Despite these benefits, blood product transfusions still were given in $38 \%$ of the VMIMS group. This red cell requirement probably resulted from longer perfusion times, with attendant hemodilution, compared with the sternotomy group. Ideally, use of packed red cells will decrease with greater operative experience and shorter cardiopulmonary bypass times.

The decision to repair a mitral valve should not be driven by the operative approach, but rather by the abnormality of the valve and the surgeon's ability. ${ }^{11}$ The quality of the final result should never be compromised to minimize hospital cost, improve cosmesis, or lessen temporary discomfort. Sixty-five percent of patients in the VMIMS group had valve repair, compared with $57 \%$ in the conventional cohort. Others also have shown a predominance of repairs done through minimal incisions. ${ }^{13}$ Follow-up times remain short; however, postoperative transesophageal echocardiographic studies suggested similar repair quality in both groups. To attain VMIMS results that are similar to results achieved with conventional mitral replacements and repairs, the surgeon must have significant sternotomy-based experience before beginning videoscopic operations.

Both "real-time" procedural economics and patient satisfaction always remain difficult to assess. In this series, overall hospital charges and costs were reduced markedly for mitral operations done by this approach. However, these reductions appeared to result mainly from shorter stays in the intensive care unit and hospital. Longer operative times for the VMIMS group clearly elevated operating room costs compared with those of the patients having conventional sternotomy. However, procedure-based operating room charges at our hospital make it difficult to calculate additive costs incurred by longer operations. Also, indications of patient satisfaction, early return to work, and discomfort are particularly difficult to determine retrospectively. In younger patients these could be major determinants for selection between a sternotomy and a minimally invasive operation. Although the VMIMS group appeared to have less postoperative discomfort, a prospective study, using appropriate psychometric measurements, is needed to clarify these issues.

Our results suggest that VMIMS procedures are safe and may benefit patients through reduced intensive care unit stays, lower transfusion requirements, less operative discomfort, earlier hospital discharge, and lower overall cost. Moreover, both mitral valve replacements and relatively complex repairs can be done by video-assisted methods with good operative results. Techniques used were modified from current practices and have the benefit of not requiring added resources. Obviously, longer term follow-up will be necessary to determine ultimate clinical outcomes. The positive features of VMIMS can be challenged because of current increased operative times and greater technical challenges. Broad experience with video assistance should diminish these concerns.

A new era in cardiac surgery is evolving, and exposure through even smaller incisions will be the bridge to truly microinvasive heart operations. To perform these operations, "extracorporeal" surgeons will need intracavitary video depth perception, improved instrument stability, computer-directed motion, and perhaps tactile feedback. Rapid acquisition of video dexterity is very important to those planning to be aboard for future minimally invasive operations. However, despite the advantages of developing technology in valve and coronary surgery, we must remain circumspect and cautious, remembering that long-term valve and graft function is the objective, not application of the technique.

We acknowledge Mr. William Hodges for perfusion technology, Ms. Laura Meadows for data analysis, Mr. Joseph Campbell for editorial review, and Mr. Michael Dulude for illustrations.

\section{REFERENCES}

1. Benetti FJ, Ballester C, Sani G, Boonstra P, Grandjean J. Video assisted coronary bypass surgery. J Card Surg 1995;10: $620-5$. 
2. Acuff TE, Landreneau RJ, Griffith BP, Mack MJ. Minimally invasive coronary artery bypass grafting. Ann Thorac Surg 1996;61:135-7.

3. Nataf P, Lima L. Regan M, Benarim S, Pavie A, Cabrol C, et al. Minimally invasive coronary surgery with thoracoscopic internal mammary dissection: surgical technique. J Card Surg 1996;11:228-92.

4. Stevens JH, Burdon TA, Siegel LC, Peters, WS, Pompili MF, St. Goar FG, et al. Port-access coronary artery bypass with cardioplegic arrest: acute and chronic canine studies. Ann Thorac Surg 1996;62:435-41.

5. Stevens JH, Burdon TA, Peters WA, Siegel LC, Pompili MF, Vierra MA, et al. Port-access coronary artery bypass grafting: a proposed surgical method. J Thorac Cardiovasc Surg 1996;111:567-73.

6. Cosgrove DM, Sabik JF. Minimally invasive approach for aortic valve operations. Ann Thorac Surg 1996;62:596-7.

7. Cosgrove DM, Sabik JF, Navia J. Minimally invasive valve surgery. Ann Thorac Surg. In press.

8. Koenertz W, Waldenberger F, Schutzler M, Ritter J, Liu J. Minimal access valve surgery through superior partial sternotomy: a preliminary study. J Heart Valve Dis 1996;5:63840.

9. Navia JL, Cosgrove DM. Minimally invasive mitral valve operations. Ann Thorac Surg 1996;62:1542-4.

10. Pompili MF, Stevens JH, Burdon TA, Siegel LC, Peters WS, Ribakove GH, et al. Port-access mitral valve replacement in dogs. J Thorac Cardiovasc Surg 1996;112:1268-74.

11. Lytle BW. Minimally invasive cardiac surgery. J Thorac Cardiovasc Surg 1996;111:554-5.

12. Mavroudis C. VATS ASD closure: A time not yet come. Ann Thorac Surg 1996;62:638-9.

13. Chitwood WR, Elbeery JR, Chapman WHH, Moran JM, Lust RL, Wooden WW, et al. Video-assisted minimally invasive mitral valve surgery: the "micro-mitral" operation. J Thorac Cardiovasc Surg 1997;113:413-4.

14. Chitwood WR, Elbeery JR, Moran JM. Minimally invasive mitral valve repair: using a mini-thoracotomy and transthoracic aortic occlusion. Ann Thorac Surg 1997;63:1477-9.

15. Schwartz DS, Ribakove GH, Grossi EA, Stevens JH, Siegel LC, St. Goar FG, et al. Minimally invasive cardiopulmonary bypass with cardioplegic arrest: a closed chest technique with equivalent myocardial protection. J Thorac Cardiovasc Surg 1996;111:556-66.

16. Falk V, Walther T, Diegeler R, Autschbach R, van Son $\mathrm{J}$, Siegel L, et al. Echocardiographic monitoring of minimally invasive mitral valve surgery using an endoaortic clamp. $\mathbf{J}$ Heart Valve Dis 1996;5:630-7.

17. Burke RP, Wernovsky G, van der Velde M, Hansen D, Castaneda AR. Video-assisted thoracoscopic surgery for congenital heart disease. J Thorac Cardiovasc Surg 1995;109: 499-507

18. Kaneko Y, Kohno T, Ohtsuka T, Ohbuchi T, Furuse A, Konishi T. Video-assisted observation in mitral valve surgery. J Thorac Cardiovasc Surg 1996;111:279-80.

19. Carpentier A, Loulmte D, Carpentier A, et al. Chirugie à coeur ouvert par vidéo-chirurgie et mini-thoracotomie: primier cas (valvuloplastie mitrale) opéré avec succès [First open heart operation] (mitral valvuloplasty) under videosurgery through a minithoracotomy]. Comptes Rendus De L'Academie des Sciences: Sciences de la vie 1996;319:219-23.

20. Chang $\mathrm{CH}$, Lin PJ, Chu JJ, Liu HP, Tsai FC, Lin FC, et al.
Video-assisted cardiac surgery in closure of atrial septal defect. Ann Thorac Surg 1996;62:697-701.

21. Lin PJ, Chang $\mathrm{CH}$, Chu JJ, et al. Video-assisted mitral valve operations. Ann Thorac Surg 1996;61:1781-7.

22. Tsai FC, Lin PJ, Chang CH, Liu HP, Tan PP, Chaing CW. Video-assisted cardiac surgery: preliminary experience in reoperative mitral valve surgery. Chest 1996;110:1603-7.

23. Kumar N, Saad E, Prabhakar G, De Vol E, Duran CMG. Extended transseptal versus conventional left atriotomy: early postoperative study. Ann Thorac Surg 1995;60:426-30.

24. Cherian KM, Pannu HS, Sankar NM, Agarwal SK, Basavaraj S, Rao SG, et al. Thoracotomy approach for congenital and acquired defects: possible applications in the current era. J Card Surg 1996;11:37-45.

25. Tribble CG, Nolan SP, Kron IL. (Update) Anterolateral thoracotomy as an alternative to repeat median sternotomy for replacement of the mitral valve. Ann Thorac Surg 1995; 59:255-6

26. Grinda JM, Folliguet TA, Dervanian P, Mace L, Legault B, Neveux JY. Right anterolateral thoracotomy for repair of atrial septal defect. Ann Thorac Surg 1996;62:175-8.

27. Kumar AS, Prasad S, Rai S, Saxena DK. Right thoracotomy revisited. J Tex Heart Inst 1993;20:40-42.

\section{Discussion}

Dr. Aubrey C. Galloway, Jr. (New York, N.Y.). I would like to thank Dr. Chitwood for presenting an innovative approach to an evolving new area of cardiac surgery. These new techniques have engendered a lot of interest. Dr. Chitwood, you performed 31 minimally invasive mitral operations with video assistance, using a right anterolateral thoracotomy incision. You demonstrated excellent results with what is apparently a safe and effective operation. There are some questions that do need to be answered, however. Whenever we introduce new techniques, we need to determine the incremental risk to the patient compared with the benefit that is achieved from the new procedure. I want to address several of these issues regarding your proposed new technique.

First, what is the need for video assistance per se? I would like to compare your series with a recent series from our institution, in which we performed approximately 100 minimally invasive valvular operations using the port-access system. We initially used a thoracoscope for visual imaging and found that it was not necessary. The Stanford group, in contrast, used the port-access system but used a more lateral incision, similar to yours, and they needed the vidoescope to visualize the valve well. We make our incision transversely in the fourth intercostal space, but more anterior and medial, and do not remove costal cartilage. We found that with the transthoracic septal cardiac retractor we can see both the anterior and the posterior leaflets well in all patients. Consequently, we abandoned the videoscope, because it added little benefit but was more cumbersome and prolonged the operating time. I note in your manuscript that you did only two anterior leaflet repairs and you suggested that one really only needs the videoscope for anterior leaflet procedures. Thus it appears there are relatively few cases in which you actually need this. Did use of the videoscopic techniques cause any problems or increase the level of difficulty? How much do you think the videoscope actually aids in per- 
forming the operation? Do you find that it is worth the cost in terms of crossclamp time? It appears from your numbers that your crossclamp times are significantly longer than you might have achieved if you had not used videoscopic imaging for suturing.

This brings up a second question. The ejection fractions were high in your patients treated by VMIMS. Only $3 \%$ to $5 \%$ of these patients had an ejection fraction of less than $40 \%$, whereas $37 \%$ of your patients having conventional sternotomy had an ejection fraction of less than $40 \%$. Because of the increased crossclamp time, did you exclude high-risk patients when using the minimally invasive techniques? Although you reported good return of cardiac function, do you think that the longer crossclamp times might lead to problems if you applied your technique to patients with low ejection fractions and pulmonary hypertension?

The third question relates to deairing techniques. How did you deair? Your method seems to be successful, inasmuch as none of your patients had a stroke. You did report some ST segment changes when you unclamped, which I presume were related to air in the aortic root. This is an important problem for minimally invasive mitral surgery because there is no access to the apex of the heart.

Finally, what is the validity of comparing two different approaches in terms of hospital costs when the groups are so different? I do not think your groups were matched well enough to provide a valid comparison. We already know that the ejection fraction was significantly better in the less invasive group. Were the anesthetic protocols, the weaning protocols, and the postoperative care maps any different? We have seen article after article showing the impact of care maps and management protocols on lowering intensive care unit stay, hospital stay, and overall cost. If these management protocols were not identical, then the cost savings and hospital stay comparisons are not valid.

Dr. Chitwood. I would like to offer my complements to your group at New York University for doing such a good job with the port-access technique and for pioneering much of this valve work. I will respond to your four questions.

First, the need for a videoscope. Initially we started doing these operations on the way to a final product that, in time, would probably be totally video-assisted valve surgery. When early on we determined that the perfusion times were longer, we looked very critically at our patients to make sure that we were doing the ethically right thing and that the patients were doing as well as they would have with other mitral operations. When we determined that the patients were doing as well, we continued to use video assistance because we believe that many of these minimally invasive operations will be video assisted ultimately.

I agree with you that a more medial incision can provide a more direct visualization. I have been able to develop video dexterity by using the camera and placing most of the sutures and doing the things that I mentioned. Without question, chordal transfers and some of the quadrangular resections are more difficult and take more time when total video assistance is used. I believe that threedimensional video assistance is on the way, and this will provide the major venue for us to do most of these mitral valve operations in a video-assisted fashion. Thus I agree with all of your comments related to direct visualization. Clearly, if I can take a nice stitch with direct visualization, I do. I use 3.5 power loupes that are corrected for the focal distance used in the minimally invasive mitral valve operations.

Second, the ejection fractions in the VMIMS cohort were better than in the conventional sternotomy group. These were consecutive patients having isolated mitral valve operations, with no coronary artery operations. That was really the only difference in this series. We did not see new dysfunction in either group in the postoperative period. Again, there were no patients with coronary disease involved in either series.

Air removal is a very important issue because the right coronary artery is clearly the closest vent provided. We did indeed encounter some ST segment changes in some of these patients. Generally these changes resolved after a period of reperfusion. We did not observe any right ventricular dysfunction. The method that I use involves an aortic root vent. We do not use a transventricular vent. We fill the ventricle meticulously, under echocardiographic control. We ventilate the lungs with the head positioned down and reclamp the aorta, letting the heart beat against the clamped aorta with the right coronary artery occluded with a sponge stick. Despite all that, we still could see a few bubbles, from time to time, going to the right coronary artery with ST segment changes ensuing. I think this is the reason that none of our patients had a stroke. The heart was beating against the clamp, evacuating air into the aortic vent. I know that you use a similar technique with the occlusion balloon.

Regarding the validity of the hospital length of stay data, the two groups were operated on at two different points in time. However, our critical care pathways were the same. Very early on, we instituted critical care and anesthetic pathways. There is no question that transfusion requirements were different because of this time difference. In this series, we had fewer transfusion requirements with similar amounts of bleeding, which leads me to believe that we transfused more liberally in earlier days.

Dr. Friedrich W. Mohr (Leipzig, Germany). Your technique describes a very simple way to achieve a minimally invasive approach to the mitral valve. In our entire series of 80 patients treated by minimally invasive mitral valve operations, I tried your approach in eight patients. My concern always is how to safely place the aortic clamp through the port and how to control the posterior wall to prevent injury to the pulmonary artery. Could you please comment on that?

Dr. Chitwood. Before addressing your question, I would like to acknowledge your work with the Heartport technology. You certainly pioneered that work.

I think the clamp can be very safely placed. It is a secure clamp, and I have not had difficulties with it. Clamping all is done with video assistance, again with the pulmonary artery visualized as the clamp is applied. We can insert a $5 \mathrm{~mm}$ camera through the transverse sinus to be sure that no injury to the left atrial appendage or the right pulmonary artery occurs as the clamp comes behind the aorta so that the clamp is positioned completely under video assistance. I have found this quite helpful. I do look several times to make absolutely sure no injury is occur- 
ring. As you would with a clamp through a sternotomy incision, I occlude the aorta very carefully, only with two or three clicks, but it all is done with video assistance.

Dr. Alain F. Carpentier (Paris, France). I rise to congratulate Dr. Chitwood and also to say a word of caution. Starting as early as February 1996, our experience comprises 22 complex mitral valve repairs with video-assisted minimally invasive techniques exploring different approaches. Whatever the approach you choose, the increased technical difficulty must be underlined. We must realize that this is extremely difficult surgery that can become maximally invasive if not done with wisdom.

The results presented by Dr. Chitwood confirm our own experience that a minimally invasive approach can be explored very carefully with no operative deaths, no idiopathic complications, no suboptimal surgical result.

I have only one question for Dr. Chitwood, who did not talk about a problem that has been disappointing for us-the pain that occurs after the approach through a sternotomy. We found that the patients complain more after thoracotomy, even minithoracotomy, as when using a ministernotomy, which is the approach we prefer today to avoid opening the pleural cavity and dividing the thoracic artery. How did you manage this problem?

Dr. Chitwood. I have to give all credit for learning about mitral valve repair to Professor Carpentier and my trips to Paris. Also, the video-assisted idea was not an original one, inasmuch as I spoke with you at last year's AATS meeting about your earlier video-assisted operations. We have continued to do some of the work that you started.

Pain is a consideration, and objective data are difficult to obtain. Surgeons cannot really say to patients, "You're not having any pain, are you?" "You've had a minimally invasive operation; you're not supposed to have any pain." True evaluation of pain is extremely difficult. I believe that when the costal cartilages are spread or resected, patients do have more pain. The patients in our series have not had a lot of pain, but we do not have a true measurement. These studies are yet to be done. We resect a segment of the bony rib, and our patients have not had a lot of pain.

I have seen your technique with the ministernotomy. Having had a sternotomy myself, I am in a unique position to evaluate operative sternal pain somewhat objectively. I believe that the ministernotomy does provide very little pain. However, we need to compare these approaches in a randomized fashion using good indices of pain. Your technique through the ministernotomy is an excellent one and is certainly just as good as my technique, if not better.

Dr. Norberto G. De Vega (Malaga, Spain). You offer us an alternative to median sternotomy for mitral valve operations to avoid long hospital stays and to provide a more cosmetic incision. We have been using such an alternative for the past 5 years. We offered our patients a somewhat larger thoracotomy, just $12 \mathrm{~cm}$, and through this incision we can do what we call $3 \mathrm{~N}$ mitral surgery: no median sternotomy, no femoral cannulation, and no myocardial ischemia. We do all of our operations with hypothermic ventricular fibrillation. We can cannulate the ascending aorta every time, and we do not use median sternotomy.

Just by adding $6 \mathrm{~cm}$ to your thoracotomy, you could avoid all the complications you have with your technique. I do not really know whether merely avoiding $6 \mathrm{~cm}$ is worth all the complications, all the things you need to think about and do, and the potential complications you have.

Dr. Chitwood. Clearly it is more difficult to do this operation with video assistance, but I think we are on a train to the new future. I believe in time we will be able to do most of these completely with video assistance.

I do agree completely with you that we must get away from femoral arterial cannulation. I have used transverse aortic arch cannulation with the Seldinger technique in four patients. I believe that through ports and small incisions we can cannulate the aorta. However, it will be a while before we feel comfortable in doing this. I like your $3 \mathrm{~N}$ technique and believe that we can avoid femoral cannulation with our technique as well. 